\title{
Scale model of a training dam using lightweight granulates
}

\author{
Bart Vermeulen ${ }^{1, *}$, Matthijs Boersema ${ }^{2}$, Ton Hoitink ${ }^{3, * *}$, Arjan Sieben ${ }^{4}$, Kees Sloff5,6, and \\ Maarten van der $\mathrm{Wal}^{5}$ \\ ${ }^{1}$ Marine and Fluvial Systems, Department ofWater Engineering and Management, Faculty of Engineer- \\ ing Technology, University of Twente, The Netherlands \\ ${ }^{2} \mathrm{HZ}$ University of Applied Sciences, Delta Academy, Vlissingen, the Netherlands \\ ${ }^{3}$ Hydrology and QuantitativeWater Management Group, Department of Environmental Sciences, Wa- \\ geningen University and Research, The Netherlands \\ ${ }^{4}$ Rijkswaterstaat Center for Water Management, Ministry of Infrastructure and the Environment, The \\ Netherlands \\ ${ }^{5}$ River Dynamics and Inland Shipping Department, Deltares, The Netherlands \\ ${ }^{6}$ Faculty of Civil Engineering and Geosciences, Delft University of Technology, The Netherlands
}

\begin{abstract}
Longitudinal training dams (LTDs) are a promising alternative for river groynes. Here we summarize findings of a recent study focused on the along river transition from a series of river groynes to an LTD, where the flow divides between the fairway and the side channel between the LTD and the river bank. A scale model is setup using lightweight granulates made of polystyrene to create conditions that are dynamically similar to a prototype situation in the River Waal. The key advantage of using lightweight granulates is that both the Shields number and the Froude number are similar in the model and the prototype. A high flow and a low flow experiment were carried out. The bedforms in the physical model have dimensions that correspond to theoretical dune height predictions, and also the channel incision due to width reduction is in accordance with expectations. The scour holes that develop near the tip of the groynes, however, are too deep, which may relate to improper scaling of the local turbulent vortices, initiated at the groynes. The morphodynamic developments in the flow divergence zone are subtle, and are overwhelmed by the mobile bed response to the presence of groynes. Considering that the physical model over-predicts the erosion caused by groynes, this suggests that the LTD configuration subject to study results in a comparatively stable bed morphology.
\end{abstract}

\section{Introduction}

Longitudinal training dams (LTDs, Fig. 1) serve to constrict the flow in the navigablepart of a river during low flows, and to increase the discharge capacity during flood conditions. In The Netherlands, the replacement of river groynes by LTDs is considered to be a key measure to prepare the Dutch rivers for the next century and beyond. The flexibility to create gaps in the dam potentially offers the opportunity to control unwanted morphological effects in the fairway and the side channel. Training dams are also expected to exert a favourable influence on habitat diversity and ecological conditions. River banks typically represent harsh

\footnotetext{
*e-mail: B.Vermeulen@utwente.nl

**e-mail: Ton.Hoitink@wur.nl
} 

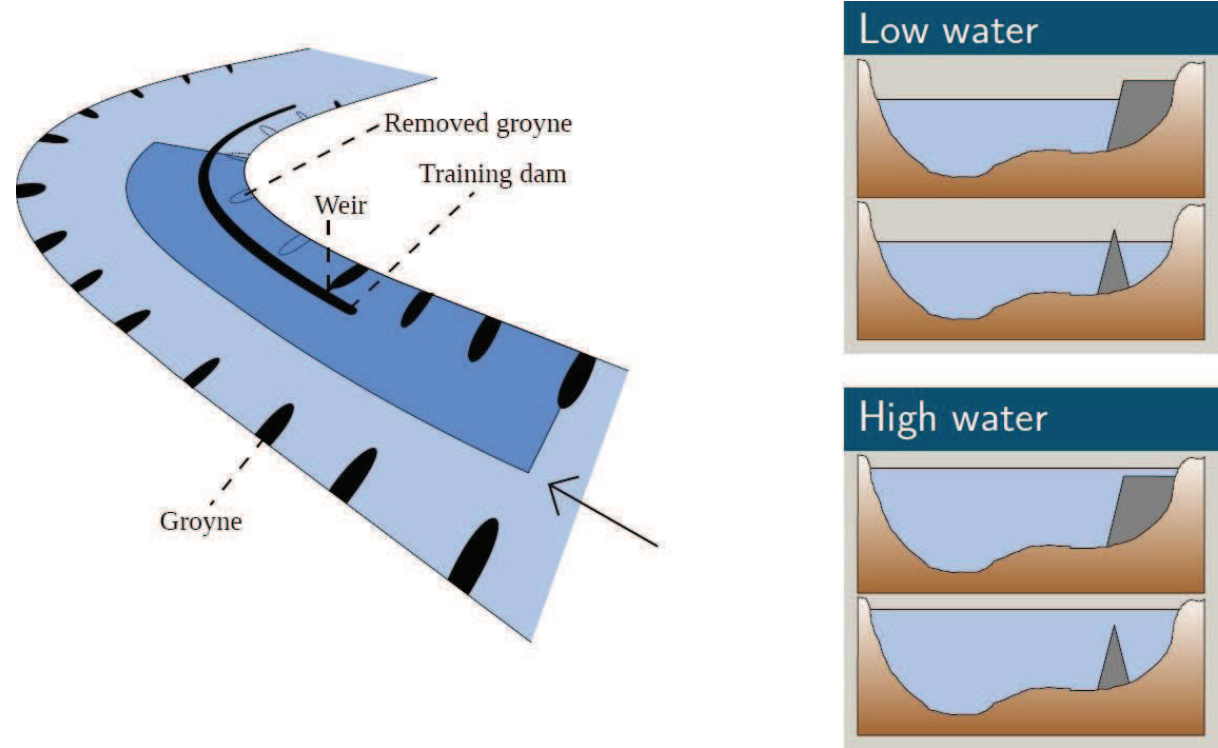

Figure 1. Schematic of a longitudinal training dam placed closer to the fairway than the present-day groynes stretch from the banks. Adapted from Vermeulen et al. [1].

environmental conditions, due to high disturbance by impacts from navigation, which causes shipping waves, water displacement and bank erosion. LTDs may create shallow and sheltered lotic habitats and gentle slopes subject to intermediate hydromorphological disturbance and supporting high biodiversity values. The objective of the ongoing project "Optimizing Longitudinal Training Dam Design" is to develop the scientific knowledge needed to optimize the design and management of longitudinal training dams in terms of navigation, flood protection and ecological rehabilitation of regulated rivers [2].

The design of an LTD and its openings should be such that the exchange of water and sediment can be controlled at low and high water stages. At low water stages, the penetration of ship-induced waves and flow should be reduced such that the disturbing influence of navigation is minimized without disconnecting the side channel completely. At high water stages, sediment transport over the LTD and through the openings will affect the bathymetry of the main channel and the side channel, depending on the local flow direction and level of turbulence. In view of erosion and aggradation of sediment, a proper lay-out of the LTD, regarding height, shape and orientation as well as the locations and shape of the openings is of paramount importance for the LTDs to meet multiple criteria. It is therefore important to achieve a thorough understanding of the transport processes associated with an LTD, and using this knowledge, to optimize the design regarding the hydro-physical and ecological consequences. Here, we report on a completed study in a laboarotory setting [1], focussing on flow and morphodynamics in the transition from a series of groynes to an LTD. In a companion paper [3], ongoing experiments are being presented for an LTD constructed at a local widening of a river.

\section{Dimensional analysis}


The variables governing flow and sediment transport in a current flume representing an alluvial river with uniform sediment read as follows:
$L \quad$ Length $(m)$
$W \quad$ Width $(m)$
$d \quad$ Depth $(m)$
$D_{50} \quad$ Median particle diameter $(m)$
$\rho_{w} \quad$ Density of water $\left(\mathrm{kg} \mathrm{m}^{-3}\right)$
$\rho_{s}-\rho_{\mathrm{w}} \quad$ Buoyant sediment density $\left(\mathrm{kg} \mathrm{m}^{-3}\right)$
$\checkmark \quad$ Kinematic viscosity $\left(m^{2} s^{-1}\right)$
$\sigma \quad$ Surface tension $\left(\mathrm{kg} \mathrm{s}^{-2}\right)$
g Gravitational acceleration $\left(\mathrm{m} \mathrm{s}^{-2}\right)$
$C \quad$ Chézy coefficient $\left(m^{1 / 2} s\right)$
$U \quad$ Velocity $\left(m s^{-1}\right)$

Dynamic similarity of flow and sediment transport in the current flume is achieved when the following non-dimensional numbers are scaled up or down with the same factor, which correspond to:

$$
\begin{gathered}
\Delta=\frac{\rho_{s}-\rho_{w}}{\rho_{w}}=\frac{\text { Gravity }}{\text { Buoyancy }} \\
\operatorname{Re}=\frac{U d}{v}=\frac{\text { Inertia }}{\text { Viscosity }} \\
W e=\frac{\rho_{w} U^{2} d}{\sigma}=\frac{\text { Inertia }}{\text { Surface tension }} \\
F r=\frac{U}{\sqrt{g d}}=\frac{\text { Intertia }}{\text { Gravity }} \\
S_{0}=\frac{U^{2}}{C^{2} d}=\frac{\text { Gravity }}{\text { Drag }}
\end{gathered}
$$

The degree of geometric similarity of the physical model proceeds from three additional scaling factors:

$$
\begin{gathered}
L_{*}=\frac{L}{d} \\
W_{*} \frac{W}{d} \\
D_{50 *}=\frac{D_{50}}{d}
\end{gathered}
$$

Strictly speaking, it is impossible to achieve dynamic similarity, if only because Froude scaling and Reynolds scaling result in different requirements when water is used in the laboratory model. Next to the Froude number, the following combined nondimensional numbers are considered sufficient to allow translating model results to the prototype: 


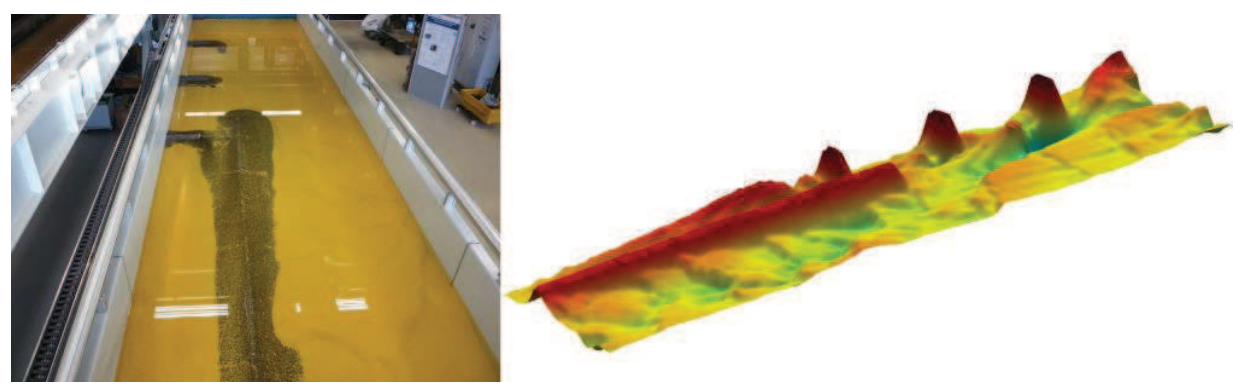

Figure 2. Laboratory setup focused on the flow transition from a series of groynes to a section of the river where the fairway is separated from the side channel by an LTD. Left: photo of the flume where the flow is from top to bottom. Right: Digital elevation model of the flume interior.

$$
\begin{gathered}
D_{*}=D_{50} \sqrt[3]{\frac{\Delta g}{v^{2}}} \\
\theta=\frac{U^{2}}{C^{2} \Delta D_{50}} \\
\gamma=2 \frac{U g W^{2}}{C^{3} d^{2} \sqrt{\Delta D_{50}}}
\end{gathered}
$$

where the dimensionless particle number $D *$ combines the effect of buoyancy, gravity and viscosity, the Shields parameter $\theta$ assures similarity of bedload sediment transport and the interaction parameter $\gamma$ represents the difference in the adjustment of flow and sediment transport to geometrical change [4].

\section{Laboratory setup}

Experiments were conducted in the Kraijenhof van de Leur Laboratory for Water and Sediment Dynamics at Wageningen University and Research. A flume with an internal width of $2.6 \mathrm{~m}$ and a length of $12.6 \mathrm{~m}$ is used, where sediment is recirculated. We chose a geometrical scaling factor of 60 relative to a prototype situation in the River Waal, and give the highest priority to similarity of the Shields number. Polystyrene granulates are used with a density of $1055 \mathrm{~kg} \mathrm{~m}^{-3}$. Using such lightweigth material, dynamic similarity occurs under relatively low flow velocities. A high flow experiment is carried out, for which the depth in the River Waal is $8 \mathrm{~m}$ and the discharge amounts to $4.600 \mathrm{~m} \mathrm{~s}^{-3}$, and a low flow experiment for which the prototype depth is $4 \mathrm{~m}$ and the discharge $1.250 \mathrm{~m} \mathrm{~s}^{-3}$. Table 1 offers a complete overview of the values of non-dimensional numbers in both experiments, compared to the prototype situation. Both the Shields number $(\theta)$ and the Froude number $(F r)$ are highly similar in the experiments and the prototype, we is the result of using lightweight granulates.

Water levels in the flume are gauged with magnetostrictive sensors and the discharge is imposed with high accuracy, using an electromagnetic flow meter. A laser elevation sensor is used to acquire 15 scans of the bed after the initial flat bed, for each experiment. Spikes in the bed level measurements were replaced based on a local weighted regression (LOESS) filter. 


\begin{tabular}{|c|c|c|c|c|c|c|c|}
\hline \multirow[t]{2}{*}{ Variable } & \multirow[t]{2}{*}{ Definition } & \multicolumn{3}{|c|}{ Low flow experiment } & \multicolumn{3}{|c|}{ High flow experiment } \\
\hline & & Prototype & Model & Scale & Prototype & Model & Scale \\
\hline$L_{*}$ & $L / d$ & 136 & 82 & 1.66 & 95 & 57 & 1.66 \\
\hline$W_{*}$ & W/d & 28 & 28 & 1 & 19.5 & 19.5 & 1 \\
\hline$D_{50^{*}}$ & $D_{50} / d$ & $2.17 \mathrm{e}-4$ & $228 \mathrm{e}-4$ & $9.5 \mathrm{e}-3$ & $2.17 \mathrm{e}-4$ & $228 \mathrm{e}-4$ & $9.5 \mathrm{e}-3$ \\
\hline$\Delta$ & $\left(\rho_{s}-\rho_{w}\right) / \rho_{w}$ & 1.65 & 0.055 & 30 & 1.65 & 0.055 & 30 \\
\hline Re & $U d / v$ & $4,165,000$ & 12,300 & 326 & $6 \mathrm{e} 6$ & 18,500 & 324 \\
\hline We & $\rho_{w} U^{2} d / \sigma$ & 74,600 & 28 & 2639 & 107,500 & 41 & 2629 \\
\hline $\mathrm{Fr}$ & $U /(g d)^{0.5}$ & 0.14 & 0.16 & 0.86 & 0.11 & 0.13 & 0.86 \\
\hline$S_{0}$ & $U^{2} /\left(C^{2} d\right)$ & $8.9 e-5$ & $13.8 \mathrm{e}-5$ & 0.64 & $6.2 \mathrm{e}-5$ & $9.6 e-5$ & 0.64 \\
\hline$\theta$ & $U^{2} /\left(C^{2} \Delta D_{50}\right)$ & 0.25 & 0.11 & 2.26 & 0.25 & 0.11 & 2.26 \\
\hline D* & $D_{50}\left(\Delta g / v^{2}\right)^{1 / 3}$ & 25 & 16 & 1.54 & 25 & 16 & 1.54 \\
\hline$\gamma$ & $\begin{array}{l}2 U g W^{2} /\left(C^{3} d^{2}\right. \\
\left.\left(\Delta D_{50}\right)^{0.5}\right)\end{array}$ & 3.84 & 2.95 & 1.30 & 1.85 & 1.41 & 1.31 \\
\hline
\end{tabular}

Table 1. Scaling of the dimensionless parameters for the high flow and low flow experiments.
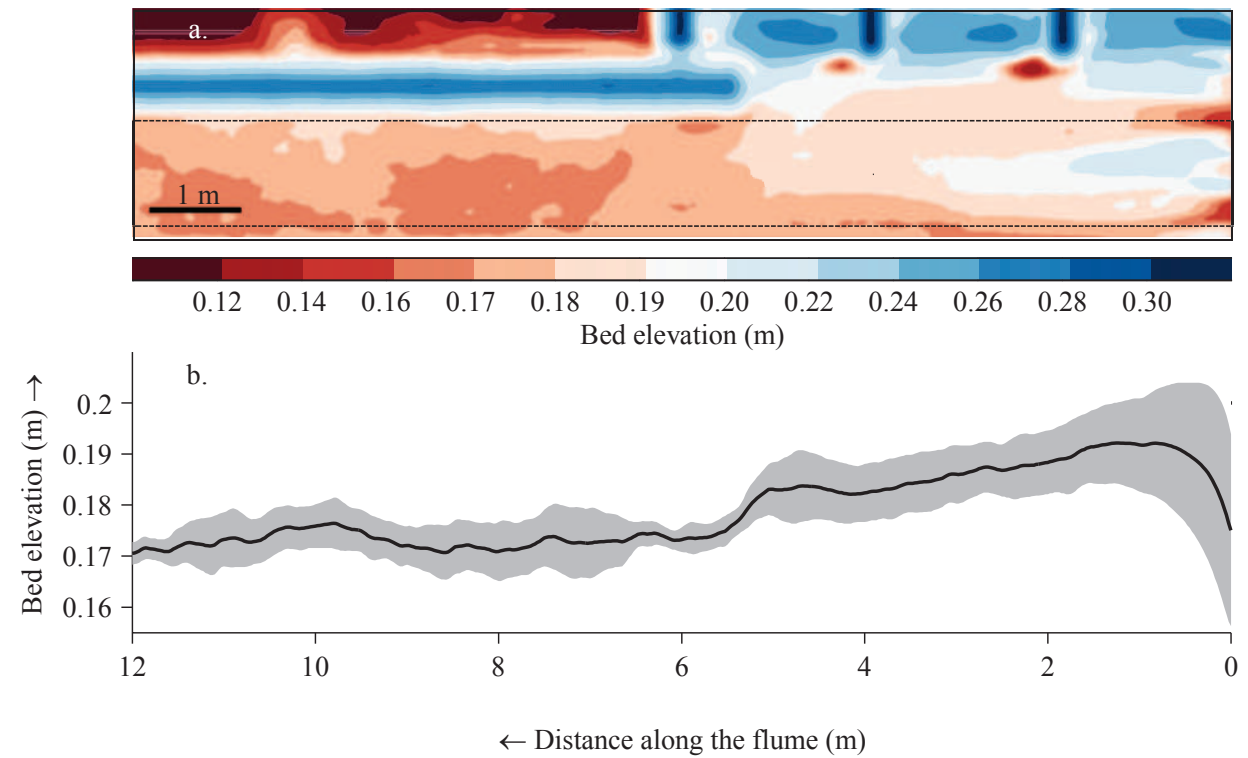

Figure 3. Plan view of the bed topography at the end of the low flow experiment (a) and terminate bed level profile obtained by averaging over the area indicated in panel a by the dashed line. The gray shaded area corresponds to region within one standard deviation from the mean profile[1].

\section{Results}

During the low-flow experiment, the areas between the groynes aggrade and next to the groyne heads scour holes develop (Fig. 3). The depth of the scour-holes is equivalent to $2.5 \mathrm{~m}$ in the model compared to a typical depth of 2.7 in the prototype. This suggests an overestimation of the scour depth in the model, because the low flow situation will not be formative. The orientation of the modeled scour holes is similar to the orientation of the 


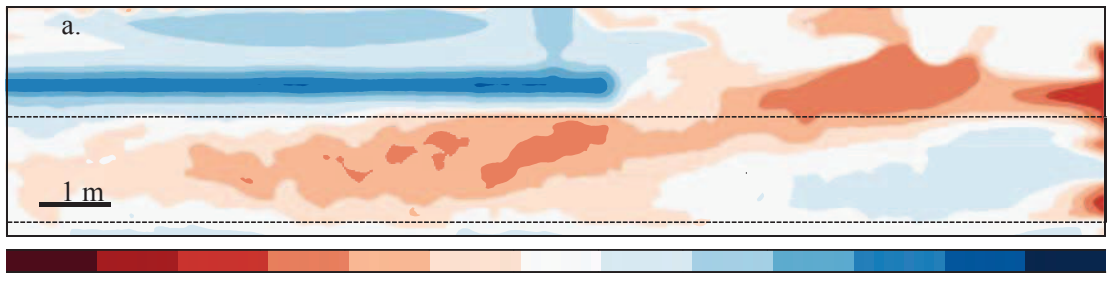

$\begin{array}{llllllllllll}0.12 & 0.14 & 0.16 & 0.17 & 0.18 & 0.19 & 0.20 & 0.22 & 0.24 & 0.26 & 0.28 & 0.30\end{array}$

Bed elevation (m)

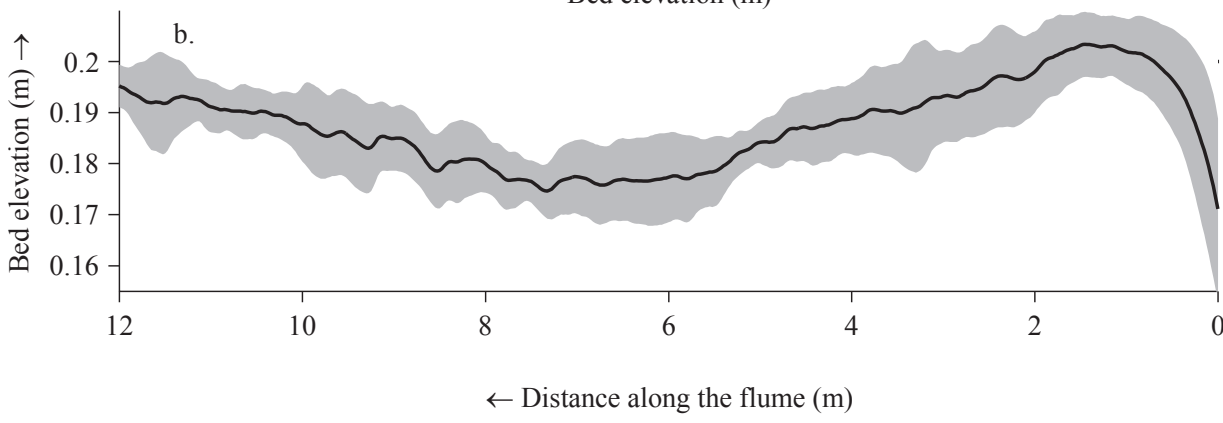

Figure 4. Plan view of the bed topography at the end of the high flow experiment (a) and terminate bed level profile obtained by averaging over the area indicated in panel a by the dashed line. The gray shaded area corresponds to region within one standard deviation from the mean profile [1].

prototype scours. The streamlines are curved near the head of the LTD. Flow separation and shedding of vortices appear to exert only a limited morphological impact on the region in the direct vicinity of the LTD.

On the riverbank side of the training dam, erosion creates a small channel, which follows the shape of the dam, connecting the head of the dam to the downstream weir in the flume. In the region next to the training dam the bed degrades. The constriction of the flow causes an increase in transport capacity, resulting in channel incision. The increase in depth next to the dam is about $3 \mathrm{~cm}$ in the model, which corresponds to $1.8 \mathrm{~m}$ in the prototype. In the region next to the training dam, the dune height is $1.5 \mathrm{~cm}$, which corresponds to a prototype height of $90 \mathrm{~cm}$. Before the training dam, the dune height is about $1.0 \mathrm{~cm}$, corresponding to $60 \mathrm{~cm}$ in the prototype. This is quite close to typical values reported for Dutch rivers, which are predicted in the range of 20 to $50 \mathrm{~cm}$ for low flow conditions [5]. Dune length fluctuates around $1.0 \mathrm{~m}$, which corresponds to $60 \mathrm{~m}$ dunes in the prototype, which seems slightly overestimated. Nevertheless, the friction factor (C) found in the model compares well with values found in the prototype.

During high flow, the bed strongly scours at the groynes, especially near the head of the first groyne where separation occurs (Fig. 4). The scour hole at the first groyne is overestimated compared to the prototype, i.e. $3.6 \mathrm{~m}$ in the model compared to $2.7 \mathrm{~m}$ in the prototype. The deepest point is closer to the groyne than in prototype conditions. The scour extends from the groyne head toward the fairway, up to the scour near the head of the training dam. Scouring at the second groyne is much smaller, and similar to the scouring observed during low flow. Sedimentation occurs between the groynes, upstream of the groyne heads.

Near the side wall of the flume, the bed is eroded. This pattern indicates conditions that are comparatively dynamic during high water. There are no local effects present near the head of the training dam, on the fairway side. A vortex street commencing at the head of 
the training dam remains close to the dam, and therefore does not induce scouring, since the excess stress is exerted on the concrete slope of the dam. The streamlining of the training dam minimizes local scouring near the head of the dam. At the bank side of the training dam, strong scouring occurs due to the inflow into the side channel, over the weir.

Deepening of the main channel section along the training dam is strongest near the head of the dam. It is not clear whether the excessive scouring near the first groyne is also affecting the region near the training dam. The reduced scouring toward the end of the flume is attributed to the higher water level, overtopping the training dam, which allows for exchange of momentum in the fairway section with the region behind the training dam, decelerating the flow. In the upstream section of the flume, sedimentation is observed in the fairway. This causes the flow to concentrate right before the first groyne. This convergence of the flow in front of the first groyne might be causing the excessive scouring. The average scour depth next to the training dam is about $1.5 \mathrm{~cm}$, corresponding to $0.9 \mathrm{~m}$ in the prototype.

In the high flow experiment, dune heights increase almost linearly along the flume from about $1 \mathrm{~cm}$ up to almost $3 \mathrm{~cm}$ corresponding to $0.6 \mathrm{~m}$ and $1.8 \mathrm{~m}$ for the prototype, respectively. These heights are within the expected range for the prototype (30 to $85 \mathrm{~cm}$ for high flow). The dune lengths remain constant around $1 \mathrm{~m}$. This corresponds to $60 \mathrm{~m}$ in the prototype and is close to values typically found in the prototype under these flow conditions, estimated as $58 \mathrm{~m}$.

\section{Conclusions}

A physical model with a mobile bed composed of polystyrene is presented, focused on the flow division at a transition from a series of river groynes to a longitudinal training dam. By using lightweight granulates, dynamic similarity was nearly achieved, both in terms of the Froude number and the Shields number. Incorrect scaling occurred only locally, where bed level gradients were largest. Compared to the prototype situation in the River Waal, the modeled dune dimensions and channel incision related to width reduction agree with expectations, yet the scour caused by groynes is exaggerated. In the direct vicinity of the region where the flow divides between the fairway and the side channel, the bed remains stable, whereas the bed morphology responds strongly to the presence of groynes. Deposition of sediment associated with flow divergence shows to be limited.

\section{References}

[1] B. Vermeulen, M.P. Boersema, A.J.F. Hoitink, J. Sieben, C.J. Sloff, M. Van der Wal, River scale model of a training dam using lightweight granulates, Journal of Hydroenvironment Research 8, 88 (2014)

[2] F. Collas, A. Buijse, L. van den Heuvel, N. van Kessel, M. Schoor, H. Eerden, R. Leuven, Longitudinal training dams mitigate effects of shipping on environmental conditions and fish density in the littoral zones of the river Rhine, Science of The Total Environment 619, 1183 (2018)

[3] T.V. De Ruijsscher, S. Naqshband, A.J.F. Hoitink, Flow Bifurcation at a Longitudinal Training Dam: Effects on Local Morphology, in Proceedings of River Flow 2018 - the Ninth International Conference on Fluvial Hydraulics (Lyon-Villeurbanne, France, 2018)

[4] N. Struiksma, K. Olesen, C. Flokstra, H. De Vriend, Bed deformation in curved alluvial channels, Journal of Hydraulic Research 23, 57 (1985)

[5] L.C. van Rijn, Sediment transport, part III: bed forms and alluvial roughness, Journal of hydraulic engineering 110, 1733 (1984) 